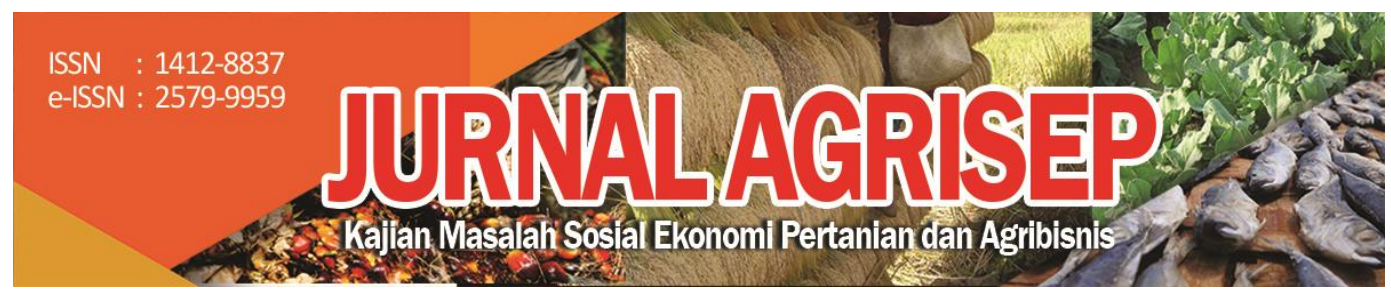

DOI: 10.31186/jagrisep.20.1.13.24

\title{
STRATEGI PENGEMBANGAN PADI LOKAL SPESIFIK LOKASI DI KABUPATEN KAPUAS PROVINSI KALIMANTAN TENGAH
}

\section{Strategy Of Specific Local Rice Development In Kapuas Regency, Central Kalimantan}

\author{
Yuni Erlina $\bigotimes_{1}$; Evi Feronika Elbaar2); Jhon Wardie ${ }^{3)}$ \\ 12)3)Program Studi Agribisnis Fakultas Pertanian Universitas Palangka Raya \\ Email: erlinayuni@agb.upr.ac.id
}

\begin{abstract}
Rice cultivation on sub-optimal land, in fact, the output is still very diverse, this requires special attention and treatment for farmers and researchers. In Kapuas district, planting local rice is one part of local wisdom that must be maintained. This study aims to examine local rice development strategies for specific locations on tidal peatlands. Data analysis using SWOT and QSPM analysis. SWOT results support an aggressive strategy for local rice / rice development in Kapuas District. The results of the QSPM analysis showed that the program priority of the Total Attractiveness Score (TAS) strategy was 6.371, with strategic policies through market development, optimal business management, expansion of rice processing businesses with organized activities, keeping maintenance sustainability of rice cultivation sawah pasang surut, giat farmer group institutionalization, increasing cooperation with the government, as well as improving the quality of human resources for young farmers.
\end{abstract}

Keywords: Local Rice, Tidal Peat, Local Wisdom, Priority Strategy

\section{ABSTRAK}

Budidaya padi pada lahan sub optimal kenyataan outputnya masih sangat beragam, hal ini memerlukan perhatian dan perlakuan khusus bagi para petani dan peneliti. Pada kabupaten Kapuas menanam padi lokal salah satu bagian kearifan lokal yang tetap harus dipertahankan. Penelitian ini bertujuan mengkaji strategi pengembangan padi lokal spesifik lokasi pada lahan gambut pasang surut. Analisis data menggunakan analisis SWOT serta QSPM. Hasil SWOT mensupport strategi agresif pengembangan padi/beras di Kabupaten Kapuas. Hasil QSPM bahwa prioritas program dari strategi Total Attractiveness Score (TAS) bernilai 6,371, dengan kebijakan strategis 
melalui pengembangan pasar, pengelolaan usaha secara optimal, perluasan usaha pengolahan beras dengan kegiatan yang terorganisir, tetap mempertahankan keberlanjutan budidaya padi sawah pasang surut, giat kelembagaan kelompok tani, peningkatan jalinan kerjasama dengan pemerintah, serta meningkatkan kualitas SDM petani berusia muda.

Kata Kunci : Padi Lokal, Gambut Pasang Surut, Kearifan Lokal, Prioritas Strategi

\section{PENDAHULUAN}

Kalimantan Tengah merupakan provinsi dengan kondisi lahan dengan kategori lahan marginal bergambut seluas 2,7 juta ha. Kenyataan bahwa kedudukan lahan marginal termasuk diantaranya lahan gambut pasang surut semakin strategis dan menjadi isu penting program Desa Peduli Gambut (PDG)(Zakirin dkk, 2013), serta Program Pengembangan Dan Pengelolaan Lahan Sub Optimal, dan Program Pencapaian Kemandirian Pangan, serta berbagai program-program lainnya (Dakhyar dkk, 2012); (Irawan, 2005). Tahun 2018, Provinsi Kalimantan Tengah memiliki luas panen padi kurang lebih sebesar 202.142 ha $( \pm 9,43 \%)$, dengan produksi padi berjumlah 742.758 ton, dengan data tersebut maka komoditas padi menempati urutan tertinggi.

Salah satu kawasan lahan gambut dan pasang surut yakni Kabupaten Kapuas, selain telah lama menjadi lumbung beras bagi Kalimantan Tengah. Berdasarkan capaian tersebut maka diharapkan terus dapat ditingkatkan supaya bukan hanya mampu tercukupinya beras di Kalimantan Tengah, tetapi dapat diterima oleh pasar eks daerah Kalimantan Tengah, guna turut ambil bagian dalam penyediaan pangan secara nasional. Kapuas tercatat sebagai 17 (tujuh belas) kecamatan penghasil padi. Pada tahun 2017, kecamatan dengan luas panen padi yang cukup tinggi yakni Kecamatan Bataguh dengan data total panen $16.542 \mathrm{Ha}$, serta Kecamatan Pulau Petak yang memiliki luas panen total luas 11.136 Ha (BPS Kabupaten Kapuas, 2018).

Produksi beras hasil output padi di Kalimantan Tengah, juga dihasilkan bukan varietas unggul saja, melainkan dari padi spesifik lokasi yang sangat toleran dan hasil output beras dengan rasa yang unik dan tentu disenangi oleh dominasi masyarakat di Kalimantan Tengah. Oleh sebab kebermanfaatan beras lokal tetap dipertahankan untuk diberdayakan oleh petani. Adapun jenis varietas padi yang banyak ditanam di Kabupaten Kapuas adalah padi varietas unggul baru (IPB 1 R Dadahup, Inpara 3, Inpari 30, Inpari 42, Inpari 43, Situ Bagendit, Towoti, Cibogo, Mekongga, Ciherang, Martapura, dan Margasari), padi varietas lokal (Siam Mutiara, Siam Pait, Siam Pangling, Karang Dukuh, Siam Kuning, Siam Pandak, Gadabung dan Manyahi), padi gogo (Garagai, Sentang dan Palun). Varietas-varietas tersebut mempunyai spesifikasi tahan genangan, toleran terhadap tanah masam, tidak

14 | Yuni Erlina, Evi Feronika Elbaar, Jhon Wardie; Strategi Pengembangan... 
mudah rebah, cukup tahan hama dan penyakit yang menyerang tanaman padi (Dinas Pertanian, 2019); (Mohi dkk, 2013).

Alwi M., (2014), menekankan bahwa lahan pasang surut memiliki peranan makin penting terutama mendukung ketahanan pangan nasional, lahan pasang surut berkontribusi terhadap produksi padi semakin besar mengingat beberapa komponen: 1). Masih luasnya lahan yang dapat dijadikan sawah, 2). Upaya untuk meningkatkan indeks panen, produktivitas lahan, dan minimalisir susut hasil melalui penerapan komponen teknologi usahatani padi yang meliputi penataan lahan dan sistem tata kelola air, komoditas dan jenis varietas yang toleran, pengelolaan lahan yang baik, ameliorasi pun pemupukan, pengendalian hama pengganggu, serta penanganan panen maupun pasca panen. Sejalan dengan itu Arsyad D.M., dkk (2014), dalam tulisannya menyatakan bahwa pemanfaatan lahan rawa pasang surut memiliki peluang sebab sudah tersedia berbagai inovasi seperti teknologi pengelolaan tanah serta air (penataan lahan, penataan mikro air, ameliorasi serta pemupukan), varietas adaptif dan produktif, serta saprotan.

Bertitik tolak dari uraian tersebut penelitian ini penting dilakukan berkait dengan kajian strategi sosial ekonomi pengembangan padi lokal spesifik lokasi yang diusahakan oleh rumahtangga petani padi pada lahan gambut pasang surut (kedalaman gambut yang diusahakan untuk pertanian $<50 \mathrm{~cm}$ ) di Kabupaten Kapuas.

\section{METODE PENELITIAN}

Penelitian dilaksanakan di Palingkau Lama, Kecamatan Kapuas Murung dan Desa Terusan Mulya, Bataguh, Kabupaten Kapuas pada Tahun 2019. Kedua wilayah tersebut memiliki data sebagai sentra produksi padi lahan pasang surut. Pengumpulan data dilakukan dengan metode survei melibatkan 67 orang petani padi lokal dan wawancara dengan 8 orang informan kunci. Data yang dikumpulkan meliputi karakteristik petani, aktivitas usahatani padi (input usahatani, produksi, permodalan, kelembagaan, pemasaran). Selain itu, dilakukan juga pengumpulan data sekunder terkait dengan data potensi padi dan output beras, ekosistem lahan, harga dan produksi secara agregat. Analisis data menggunakan SWOT serta QSPM (Kay, 1981); (Rangkuti, 2016); (Taslimi \& Ommeyr, 2014); (Harience dkk, 2016).

\section{HASIL DAN PEMBAHASAN}

\section{Profil Lokasi}

Padi lokal yang spesifik lokasi pada pasang surut di Kabupaten Kapuas adalah satu kearifan lokal dipertahankan bagian besar petani. Berbagai teknologi pun dilaksanakan dari mulai benih unggul, sistem pertanaman, teknologi, 
saprodi maupun saprotan secara perlahan namun pasti membawa perubahan di bidang pertanian pertanaman padi di lahan gambut pasang surut (Erlina dkk, 2019).

Ada suatu keunikan tersendiri dalam menanam padi spesifik lokasi sebab benih yang digunakan adalah unggul lokal, sementara itu dalam pengelolaannya kondisi lahan sangat tergantung pasang surut air laut yang membutuhkan pengetahuan khusus (Noor, 2014); (Hariyanto dan Basuki, 2013). Faktor penting modal petani salah satunya yakni lahan (Bruce R. Beattie, et al, 2006). Lokasi lahan petani dalam pengelolaannya rata-rata termasuk wilayah terkena luapan pasang tunggal (tipe B).

\section{Kekuatan dan Kelemahan Pengembangan Padi Lokal}

Beberapa kekuatan dari segi Faktor internal usahatani padi di Kabupaten Kapuas, dimana kekuatan internal tertinggi yakni pada faktor keinginan kuat dalam upaya pengembangan usaha dengan bobot sebesar 0,160 serta nilai rating 4,000 maknanya bahwa kekuatan menunjukkan peluang penting sehingga kekuatan tersebut harus dipertahankan. Kedua, faktor internal nilai bobot 0,120 serta rating 3,000 terutama terdapat pengalaman petani, potensi lahan, serta kemudahan dalam pemeliharaan dan perawatan, memberi makna bahwa faktor tersebut memberikan pengaruh penting.

Kelemahan internal lainnya antara lain minimnya tingkat pendidikan formal, sarana penyimpan masih belum merata serta belum modern, modal terbatas, sarana dan prasarana pengangkut kurang memadai, ditambah kurangnya informasi harga. Faktor internal yang dengan bobot nilai 0,040, rating 1,000 memberi makna bahwa pengaruhnya sedikit penting terhadap usahatani, dan kelemahan cukup tinggi sehingga kelemahan itu harus segera diperbaiki. Faktor internal dengan bobot 0,080 dan rating dengan nilai 2,000 memberi makna bahwa faktor tersebut agak penting berpengaruh pada usahatani serta kelemahan yang diberikan cukup besar sehingga harus mendapat support perbaikan.

\section{Peluang dan Ancaman Pengembangan Padi Lokal}

Sisi faktor eksternal memiliki peluang permintaan beras yang selalu meningkat, tingginya harga beras dibanding jenis beras lainnya, kemampuan produksi beras, tersedia lahan untuk pengembangan usaha. Faktor eksternal memiliki bobot 0,154 dan nilai rating sebesar 4,000 memberi makna bahwa pengaruhnya sangat penting bagi usaha pun peluang yang tinggi sehingga peluang perlu pemanfaatan secara maksimal. Bobot faktor eksternal 0,115 dan rating bernilai 3,000 memberi makna pengaruh penting terhadap peluang usaha. 


\section{Perumusan Strategi Pengembangan Padi Lokal}

Faktor-faktor internal (kekuatan dan kelemahan) maupun eksternal (peluang dan ancaman) pengelolaan padi lokal di Kabupaten Kapuas sangat beragam (Erlina dkk, 2019). Output analisis tersebut disusun beberapa alternatif strategi yang mendasarkan pada penggabungan elemen faktor internal pun eksternal dalam martiks SWOT disajikan di Tabel 1.

\section{Tabel 1. Matrik SWOT Perumusan Strategi Komoditas Padi/Beras di Kabupaten Kapuas, 2018}

\begin{tabular}{|c|c|c|}
\hline EFAS & $\begin{array}{ll}\text { Kekuatan }(S) \text { : } \\
\text { 1. } & \text { Keinginan kuat dalam } \\
\text { mengembangkan usaha. } \\
\text { 2. Pengalaman petani. } \\
\text { 3. Kondisi lahan cocok. } \\
\text { 4. Pemeliharaan dan } \\
\text { perawatan mudah. } \\
\text { 5. Benih cocok. }\end{array}$ & 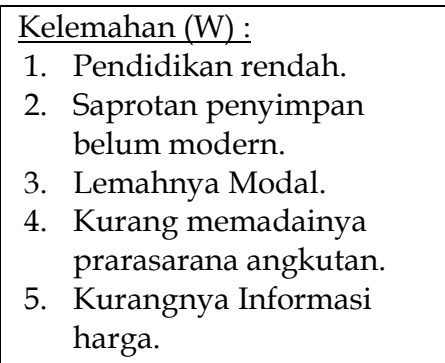 \\
\hline $\begin{array}{ll}\text { Peluang }(\mathrm{O}) \text { : } \\
\text { 1. } \\
\text { Permintaan beras } \\
\text { 2. Tingginga harga beras. } \\
\text { 3. Kemampuan produksi } \\
\text { besar } \\
\text { 4. Lahan tersedia. } \\
\text { 5. Tersedianya program } \\
\text { lahan sub optimal. }\end{array}$ & $\begin{array}{l}\text { Kebijakan Strategi (SO): } \\
\text { 1. Optimalisasi tata kelola } \\
\text { usaha. } \\
\text { 2. Perluasan pasar. } \\
\text { 3. Organisi usaha. } \\
\text { 4. Peningkatan kawasan } \\
\text { budidaya berkelanjutan. }\end{array}$ & 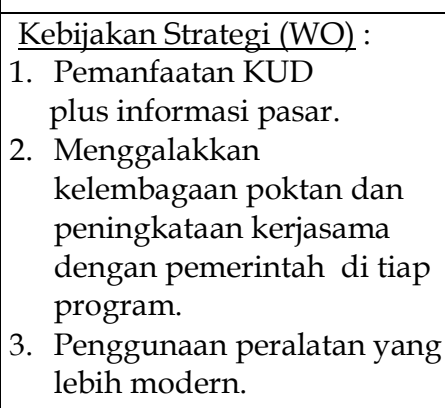 \\
\hline $\begin{array}{l}\text { Ancaman }(\mathrm{T}) \text { : } \\
\text { 1. Rendahnya penguasaan } \\
\text { teknologi. } \\
\text { 2. Sering terjadi } \\
\text { pembatalan transaksi. } \\
\text { 3. Terbatasnya persediaan } \\
\text { beras. } \\
\text { 4. Adanya pesaing. } \\
\text { 5. Konversi lahan } \\
\text { pertanian merajalela. }\end{array}$ & $\begin{array}{l}\text { Kebijakan Strategi (ST): } \\
\text { 1. Terapan Teknologi. } \\
\text { 2. Peningkatan volume } \\
\text { output. } \\
\text { 3. Upaya mempertahankan } \\
\text { mutu beras. }\end{array}$ & 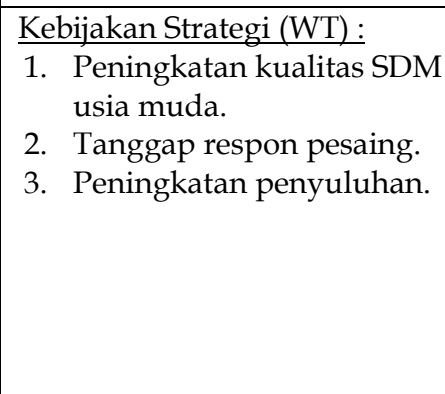 \\
\hline
\end{tabular}

Sumber : Data Primer, 2019.

Uraian pada Tabel 1 dapat dirumuskan 6 strategi pengembangan padi lokal yaitu: (1) Optimalisasi tata kelola usaha, (2) perluasan pasar, (3) Organisisi usaha, (4) Peningkatan kawasan padi berkelanjutan, (5) Menggalakkan kelembagaan poktan serta peningkatan kerjasama pemerintah pada tiap-tiap program, dan (6) Meningkatkan kualitas SDM petani berusia muda. 
Berdasarkan hasil analisis QSPM maka strategi yang tepat diterapkan pada usahatani padi pasang surut tersebut yaitu S-O (Kekuatan-Peluang) dengan kebijakan strategi pengembangan produk usahatani padi melalui:

\section{Pengembangan Pasar}

Posisi sektor hulu dalam upaya meningkatkan produksi padi bukan merupakan satu-satunya upaya, tetapi juga penting dari sektor hilir yakni dari sisi pasar, hal ini ditunjang dari tingkat permintaan konsumen terhadap beras lokal. Petani/produsen dapat melakukan strategi yaitu dengan pengembangan pasar atau dengan cara memperluas jaringan pasar (Sobichin, 2013). Jaringan pasar yang dapat direkomendasikan untuk dikembangkan yakni mulai dari petani/produsen, penggilingan padi/beras yang ada di daerah penelitian serta BULOG (Badan Urusan Logistik). Dengan demikian pengembangan pasar mampu menampung hasil beras dan persediaan beras, selain itu diharapkan petani mendapatkan keuntungan yang lebih besar jika hanya menjual pada satu pedagang pengumpul saja. Dalam hal ini petani dituntut untuk lebih kreatif serta banyak mencari sumber-sumber informasi pasar.

\section{Pengelolaan Usaha secara Optimal}

Minat yang kuat dan pengalaman dalam pengelolaan lahan dari petani merupakan modal dasar dari petani untuk mengembangkan usaha yang ada, terutama melalui peningkatan indeks pertanaman dengan menanam tanaman padi minimal dua kali tanam dalam setahun, serta mengoptimalkan penggunaan sarana dan prasarana produksi, sehingga dapat meningkatkan pendapatan yang diperoleh oleh rumahtangga petani. Hal ini dilakukan mengingat permintaan beras semakin meningkat, harga beras semakin tinggi, lahan untuk pengembangan produksi padi cukup luas, serta tersedianya program pengembangan lahan sub optimal yang digaungkan oleh pemerintah. Petani juga dapat memanfaatkan program-program yang dilaksanakan oleh Dinas Pertanian setempat melalui usahatani padi unggul dan lokal, sehingga kegiatan usahatani padi/produksi beras maupun distribusi beras dapat lebih dikembangkan .

\section{Perluasan Usaha Pengolahan Beras dengan Kegiatan yang Terorganisir}

Usaha-usaha pengolahan beras pada lokasi penelitian yang ada di Kabupaten Kapuas masih tergolong skala kecil dan belum terorganisir. Strategi yang dapat dilakukan selain faktor-faktor diatas, yakni dengan melakukan perluasan usaha dengan membuat jaringan agribisnis dari hulu ke hilir sehingga dapat dilakukan dengan jumlah besar dan sistem 
yang terorganisasi. Hal ini bertujuan agar kegiatan dapat dilakukan secara teratur dan berkelanjutan (Sobichin, 2013); (Yusuf, 2016).

\section{Meningkatkan Kawasan Budidaya Padi Secara Berkelanjutan}

Kawasan pasang surut yang dapat dikembangkan di Kalimantan Tengah sejalan dengan pendapat Sulaiman (2018) yakni seluas 13,9 juta hektar, termasuk Kabupaten Kapuas tersedia masih sangat luas. Data tersedia yang sudah dikembangkan untuk tanaman padi di Kalimantan Tengah adalah seluas 193.489 hektar. Hal ini sejalan juga dengan program pengembangan lahan sub optimal yang sudah dan sedang dilakukan oleh pemerintah. Pemerintah Kalimantan Tengah tahun 2018 menargetkan lahan sub optimal seluas 11.500 hektar untuk padi, salah satu terdapat di Kabupaten Kapuas dengan upaya realisasi lahan sawah seluas 1.390 hektar.

\section{Menggalakkan Kelembagaan Poktan Dan Peningkatan Kerjasama Dengan Pemerintah Di Tiap Program}

Kelembagaan kelompok tani pada lokasi penelitian masih terbatas, masih banyak petani atau rumahtangga petani yang belum tergabung dalam kelompok tani, terlebih petani swadaya dengan potensi lahan yang cukup luas serta sudah berorientasi pada pasar. Sasaran pembentukan kelembagaan kelompok tani yang berada pada satu hamparan dapat diperluas, hal ini untuk memudahkan pembinaan terhadap petani (Basudewo, 2015); Rizky B.,P., 2014); (Krisna, 2015). Demikian halnya untuk tenaga penyuluh dapat ditambah dan lebih ditingkatkan lagi pelayanan terhadap para petani dan rumahtangga petani.

\section{Meningkatkan Kualitas SDM Petani Berusia Muda}

Berdasarkan hasil penelitian bahwa rendahnya sumberdaya manusia di tingkat pendidikan petani rendah yakni sebesar 45,71 persen sampai dengan 53,13 persen, dan sejalan juga dengan data yang didapat dari BPS. Pendidikan dapat diperoleh dari kegiatan-kegiatan dari sektor nonformal berupa pelatihan-pelatihan dalam rangka pengembangan tanaman padi.

Berdasarkan hasil penelitian dan juga didasarkan kepada beberapa tahap pendekatan yang ada, maka dapat dibuat rancangan strategi pengembangan padi pada lahan pasang surut (Gambar 1), dengan rentang waktu lima tahun ke depan dapat dijelaskan menggunakan sumbu $X$ maupun $Y$, dimana $X$ merupakan strategi yang akan dijalankan, sedangkan sumbu $\mathrm{Y}$ merupakan 
waktu dalam pelaksanaan strategi pengembangan usaha padi Pola II dengan beberapa tantangan yang dihadapi. Strategi dapat dilaksanakan secara per tahap dari tahun ke tahun terdiri dari pengembangan pasar, pengelolaan usaha secara optimal, meningkatkan kawasan budidaya padi yang berkelanjutan meningkatkan kualitas sumberdaya manusia petani berusia muda, dengan sasaran yang ingin dicapai yakni meningkatkan produksi dan pendapatan petani padi lokal spesifik lokasi.

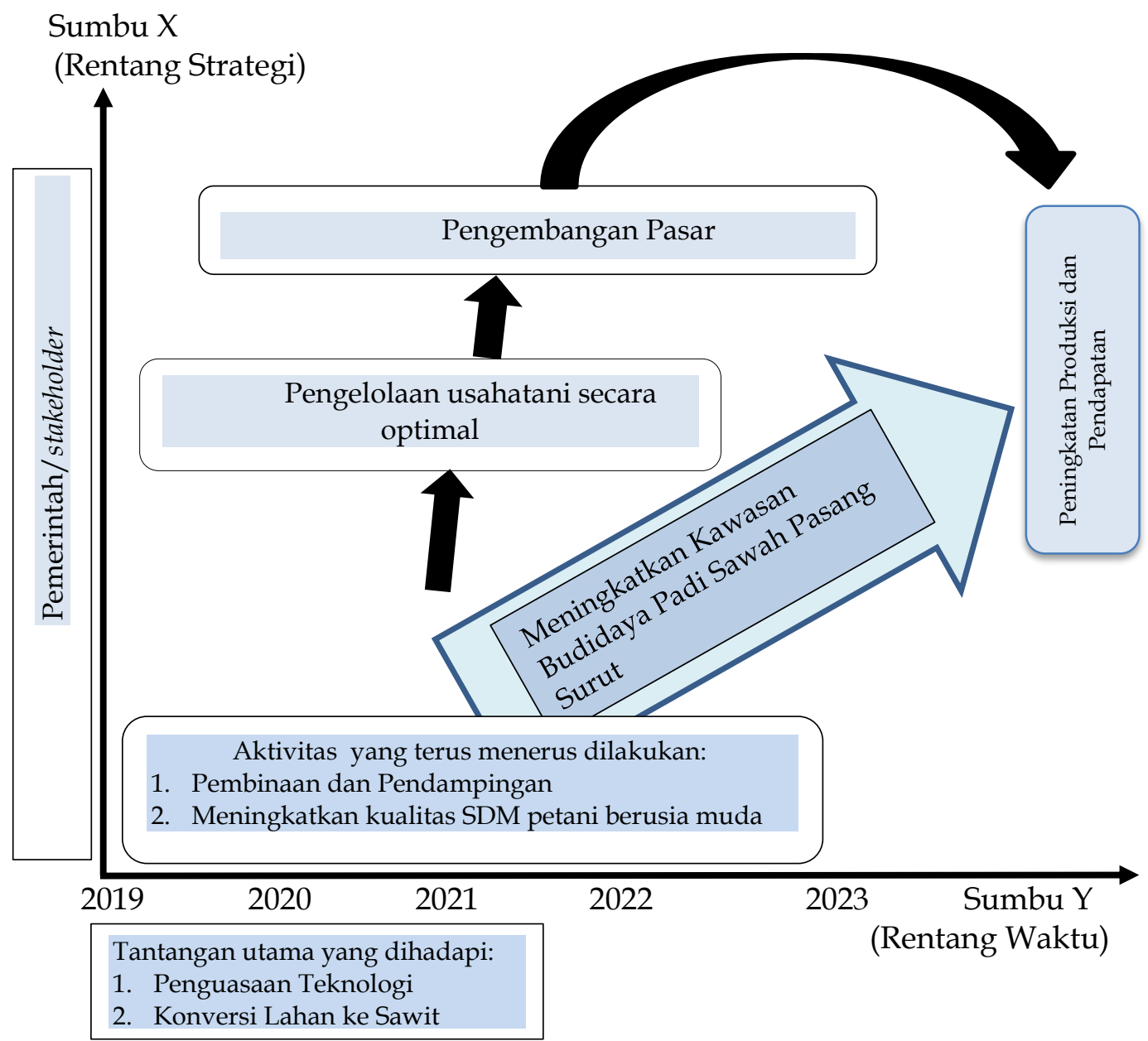

Sumber: Hasil Olah Data Primer, (2019)

Gambar 1.

Rancangan Strategi Pengembangan Padi Lokal

20 | Yuni Erlina, Evi Feronika Elbaar, Jhon Wardie; Strategi Pengembangan... 


\section{Prioritas Strategi Pengembangan Padi Lokal}

Setelah penyusunan strategi pengembangan padi lokal, maka perlu dilakukan prioritas strategis agar membantu pengambil kebijakan dapat manajemen program. Penyusunan prioritas tersebut menggunakan analisis QSPM, dengan nilai QSPM sebesar 6,371. Hasil analisis QSPM dapat dilihat pada Tabel 2.

\section{Analisis Quantitive Strategic Planning Matrix (QSPM)}

Tahap setelah input analisis melalui matrik IFAS dan EFAS, pencocokan matrik SWOT, selanjutnya tahap keputusan dengan analisis QSPM. Hasil output secara objektif ada indikasi alternatif mana yang terbaik. Hasil analisis QSPM lihat pada Tabel 2.

\section{Tabel 2. Quantitive Strategic Planning Matrix Prioritas Strategi Pengembangan Padi Lokal di Kabupaten Kapuas}

\begin{tabular}{lccc}
\hline \multirow{2}{*}{\multicolumn{1}{c}{ Strategi }} & & \multicolumn{2}{c}{ Prioritas Strategi } \\
\cline { 3 - 4 } & \multirow{2}{*}{ Bobot } & \multicolumn{2}{c}{ Strategi Pola II } \\
\cline { 3 - 4 } & & AS & TAS \\
\hline Optimalisasi usaha & 0,554 & 2,000 & 1,108 \\
\hline Pengembangan pasar & 0,558 & 3,000 & 1,674 \\
\hline Usaha terorganisir & 0,583 & 2,000 & 1,166 \\
\hline Peningkatan kawasan padi berkelanjutan & 0,549 & 3,000 & 1,647 \\
\hline $\begin{array}{l}\text { Menggalakan kelembagaan Poktan dan peningkatan } \\
\text { kerjasama pemerintah di tiap program }\end{array}$ & 0,349 & 1,000 & 0,349 \\
\hline Meningkatkan kualitas SDM petani berusia muda & 0,078 & 1,000 & 0,078 \\
\hline \multicolumn{2}{c}{ Total } & & 6,371 \\
\hline
\end{tabular}

Sumber: Data Primer, 2019

Pada Tabel 2, teridentifikasi enam strategi yang dapat dikembangkan dari hasil analisis SWOT kemudian diintegrasikan melalui QSPM untuk ditetapkan sebagai strategi prioritas. Hasil analisis SWOT terdapat tiga strategi penting mengikuti Pola II dari strategi S-O sampai WT, maka ditentukan lagi peringkat prioritas strategi dengan melakukan pengembangan pasar untuk memperluas pasar produk. Alternatif strategi selanjutnya adalah dengan cara meningkatkan kawasan budidaya padi pasang surut mengingat masih luasnya areal yang masih tersedia secara bertahap, yang tentunya sejalan dengan program pengembangan lahan sub optimal. Ketiga, yakni memperluas usaha secara terorganisir dengan membuat jaringan agribisnis dari hulu ke hilir. Nilai-nilai tersebut menunjukkan nilai strategi terbaik dalam pengembangan padi lokal pada gambut pasang surut. Strategi tersebut juga menjadi strategi terbaik ditinjau dari sosial ekonomi petani padi lokal untuk lebih meningkatkan usahatani serta pendapatan petani. 


\section{SIMPULAN DAN SARAN}

\section{Simpulan}

Kebijakan strategi yang dapat diterapkan bagi petani antara lain pengembangan pasar, pengelolaan usaha secara optimal, perluasan usaha pengolahan beras dengan kegiatan yang terorganisir, peningkatan kawasan budidaya padi secara berkelanjutan (Noor, 2014), menggalakkan kelembagaan poktan dan peningkatan kerjasama dengan pemerintah berbagai program, serta meningkatkan kualitas sumber daya manusia petani yang berusia muda. Hasil QSPM prioritas program strategi S-O dengan WT Total Attractiveness Score strategi terbaik ditinjau dari sosial ekonomi petani padi lokal untuk lebih meningkatkan produksi usahatani serta pendapatan petani adalah pengembangan pasar, meningkatkan kawasan budidaya padi pasang surut, serta memperluas usaha secara terorganisir dengan membuat jaringan agribisnis dari hulu ke hilir.

\section{Saran}

Pengembangan padi di Kabupaten Kapuas disarankan kepada Pemerintah Daerah agar lebih fokus pada tiga aspek utama pengembangan padi lokal yakni pengembangan pasar, meningkatkan kawasan budidaya padi pasang surut, serta memperluas usaha secara terorganisir dengan membuat jaringan agribisnis.

\section{DAFTAR PUSTAKA}

Alwi Muhammad. 2014. Prospek Lahan Rawa pasang Surut Untuk Tanaman Padi. Prosiding Seminar Nasional "Inovasi Teknologi Pertanian Spesifik Lokasi". Banjar Baru 6-7 Agustus 2014. Hal. 45-59.

Arsyad D.M., Saidi B.B., dan Enrizal. 2014. Pengembangan Inovasi Pertanian Di Lahan Rawa Pasang Surut Mendukung Kedaulatan Pangan. Balai Besar Pengkajian dan Pengembangan Teknologi Pertanian. Jurnal Pengembangan Inovasi Pertanian 7(4): 169-176.

Basudewo Krisna Jumna, 2015. Strategi Pengembangan Usahatani Dalam Upaya Peningkatan Produksi Padi Organik. Economics Development Analysis Journal. EDAJ 4 (2): 233-241.

22 | Yuni Erlina, Evi Feronika Elbaar, Jhon Wardie; Strategi Pengembangan... 
BPS Kabupaten Kapuas. 2018. Kabupaten Kapuas Dalam Angka. Katalog 1102001.6203. Kabupaten Kapuas.

Bruce R. Beattie, C. Robert Taylor. 2006. Ekonomi Produksi. Fakultas Ekonomi. Universitas Gadjah Mada. Yogyakarta.

Dakhyar N., Hairani, dan Indrayati. 2012. Prospek Pengembangan Penataan Lahan Sistem Surjan Di lahan Rawa Pasang Surut. Jurnal Agrovigor. 5(2): 113-118.

Erlina Y., Elbaar Evi F., Wardie J., 2019. Analisis Faktor Sosial Ekonomi Pengembangan Padi Lokal Spesifik Lokasi Di Kabupaten Kapuas Provinsi Kalimantan Tengah. Prosiding Seminar Nasional Lingkungan Lahan Basah. 5(1):61-68 April 2020. Web: snllb.ulm.ac.id.

Hariance R., Febriamansyah R., Tanjung F., 2016. Strategi Pengembangan Agribisnis Kopi Robusta Di Kabupaten Solok. AGRISEP.15 (1): 111-126. Hariyanto W., dan Basuki Seno, 2013. Identifikasi Beberapa Kearifan Lokal Dalam Menunjang Keberhasilan Usahatani Padi Di Jawa Tengah. Balai Pengkajian Teknologi Pertanian Jawa Tengah. Diakses Pada Tanggal 03 Mei 2019.

Irawan, B., 2005. Konversi Lahan Sawah: Potensi Dampak, Pola Pemanfaatannya, dan Faktor Determinan. Forum Penelitian Agroekonomi, 3(1): 1-18.

Kay, R. D., 1981. Farm Management Planing Control and Implementation. International Student Edition. Mc Graw Hill International Book Company. New York.

Krisna B. J., 2015. Strategi Pengembangan Usahatani Dalam Upaya Peningkatan Produksi Padi Organik. Economics Development Analysis Journal. Volume 2(4). Halaman 446-455.

Mohi Widya K., Amir., Mopangga H., 2013. Analisis Strategi Pengembangan Pertanian Melalui Pengendalian Hama Terpadu (PHT) Padi Kabupaten Gorontalo. Jurnal Ilmu Administrasi. 2(2):11-14.

Noor, Muhammad, 2014. Prospek Pertanian Berkelanjutan di Lahan Gambut: dari petani ke Peneliti dan Peneliti ke Petani. Balai Penelitian Lahan Rawa Banjar Baru. URL: repository.pertanian.go.id.

Rangkuti, F. 2016. Teknik Membedah Kasus Bisnis Analisis SWOT. Gramedia Pustaka Utama. Jakarta.

Rizky, Bayu Pratama, H. N. S., 2014. Strategi Pengembangan Usahatani Kedelai Untuk Mewujudkan Ketahanan Pangan Indonesia. JEJAK Journal of Economics and Policy. 7(2): 109-120.

Sobichin, M., 2013. Nilai Rantai Distribusi Komoditas Gabah Dan Beras Di Kabupaten Batang. Economics Development Analysis Journal, 2(1): 1-11.

Taslimi, M. S., \& Ommeyr, A. K. 2014. Formulating a strategy through quantitative strategic planning matrix (QSPM) based on SWOT 
framework (Case study: industrial group of Barez Tires). International Journal of Economy, Management and Social Sciences, 3(8), 451-457.

Yusuf, Arif Harnali S.S., M., 2016. Pemahaman Strategi Bisnis Dan Kewirausahaan. Jakarta. Prenadamedia Group.

Zakirin M., Yurisinthae E., Kusrini N., 2013. Analisis Risiko Usahatani Padi Pada Lahan Pasang Surut Di Kabupaten Pontianak. Jurnal Social Economic of Agriculture, 2(1): 75-84.

24 | Yuni Erlina, Evi Feronika Elbaar, Jhon Wardie; Strategi Pengembangan... 